\title{
Patterns of Family Identifications in Adolescents from Different Backgrounds
}

\author{
Silvia Maués Santos Rodrigues ${ }^{1}$, Janari da Silva Pedroso², \\ Fernando Augusto Ramos Pontes ${ }^{1}$, Christoph 0. Käppler ${ }^{3}$, \\ Júlia Sursis N. F. Bucher-Maluschke4 \\ ${ }^{1}$ Theory and Research of Behaviour Post Graduation Program, Federal University of Pará, Belém, Brazil \\ ${ }^{2}$ Psychology Post Graduation Program, Federal University of Pará, Belém, Brazil \\ ${ }^{3}$ Faculty of Rehabilitation Sciences, Social and Emotional Development in Rehabilitation and Education, \\ Technical University of Dortmund, Dortmund, Germany \\ ${ }^{4}$ Catholic University of Brasilia, Brasilia, Brazil \\ Email: silviamaues@ufpa.br
}

Received 12 August 2015; accepted 15 September 2015; published 21 September 2015

Copyright (C) 2015 by authors and Scientific Research Publishing Inc.

This work is licensed under the Creative Commons Attribution International License (CC BY). http://creativecommons.org/licenses/by/4.0/

(c) () Open Access

\section{Abstract}

This exploratory study aims to examine the family identification patterns obtained with the Family Identification Test (FIT) in 1082 adolescents, by subgroups from different backgrounds including subgroup of outpatient treatment for mental disorders (clinical group, CG), and subgroups of students from regions with low and high human development index: public school group (PG), and private school group (PrG), in order to explore discriminant properties of the instrument and its utility to monitor mental health outcomes in adolescents. The FIT allows one to describe different self-concepts (self-congruence, actual and ideal self-image), and the perception of others (father's image, mother's image, etc.) by using twelve attributes related to three common personality dimensions (extraversion, neuroticism and agreeableness). The correlation between those concepts indicates the patterns of identification. Statistical analyzes were performed to test the hypothesis that there would be one or more differences of means between the groups and the results of the FIT. A statistically significant effect was obtained with MANOVA followed by a series of ANOVAs that indicated differences in family identification patterns. The adolescents from PrG showed higher means than adolescents from PG in auto-congruence, actual and ideal identification with the father and ideal identification with grandparent variables; and also showed differences with the CG in actual and ideal identification with the father. The results differentiated adolescents from different backgrounds. Adolescents from clinical and public schools groups reported a smaller desire to look like their fathers, which might have some clinical significance like lower cohesion or family attachment or more pronounced feelings of rejection with father figure. Future studies are needed to analyze these findings over time and in representative population samples. 


\section{Keywords}

\section{Adolescent, Self-Concept, Self-Congruence, Actual Self, Ideal Self, Family}

\section{Introduction}

Adolescents experience important phase of its development, and that is marked inexorably by the presence of early sexual maturation signals and triggered by puberty, which changes their bodies and also how they begin to see themselves and how they are perceived and treated by others (Call et al., 2002; Garcia, 2010).

It is understood the adolescence as the time when individuals are most concerned with establishing a sense of inner identity. The relation between identification and identity is more important during adolescence when the jump from parental identification to peers and other people (as leader figures outside the family) contributes to the formation of a more stable personal identity. By identifying with others and imitating certain characteristics of others, the adolescent builds its own identity (Erikson, 1968/1994).

The family identification processes represent a crucial moment in the development and organization of family relationships (partner relationships, parent-child relationships). In addition, they play an important role in the development of self-concept and, therefore, of personality and mental health; in the last analysis, they will affect the psychosocial development of children (Remschmidt \& Mattejat, 1999).

\subsection{The Concept of Identification}

The term identification is used in various theoretical approaches and therefore, understanding it depends on the basis of which it is based on. In order to better define the meaning of the term in this paper, its origin will be highlighted according to the main theoretical approaches of support, namely, psychoanalytic, social learning and cognitive theories.

In psychoanalytic theory, its origin goes back to the Oedipal scene. The original draft, based on the Greek tragedy Oedipus Rex (Sófocles, 1997), was presented by Freud in 1897 in a letter to Fliess (Freud, 1950/2006); achieved the status of founder concept with the publication of the Oedipus Complex Dissolution (Freud, 1924/2006) and came to represent crucial role in the subject's constitution. Identification is presented as a solution to the oedipal scene; at the positive Oedipus, a male child, facing the anxiety experienced by the threat of castration, leaves the cathexis directed to the mother (primary identification), replacing them with identifications with the father (secondary identification). The paternal authority is internalized into the ego, perpetuates the prohibition against incest and encourages the construction of the superego morality and the rise of the other in the subject constitution (Moreira, 2004).

Similarly, in the theories of learning, identification with one parent is considered as a central process for the development of self-image and personality. However, this will occur under conditions similar to imitation and, in contrast to psychoanalytic theory, the imitation of same-sex parents is related to positive reinforcements linked to the conduct to be emulated and not for the castration fear by rival quality directed to fathers or mothers (Bandura, 1969). An individual can identify with a model, not only to reduce anxiety due to the anticipated aggression. The motivation for the acquisition and keeping of identification response is related to the desire to achieve positive target states dominated by the model beyond the mastery of the environment and the loving support. Reinforcement for acquiring identification occurs because of the attributes of perceived similarity between the person and the model. Once identification has been established, the individual behaves as though the model of the target states belong to it; in turn, this positive effect derived from vicarious sharing also helps to keep identification. In addition, the individual can be identified in varying degrees, with a variety of models (Kagan, 1958).

In cognitive approaches, whose foundation takes place from the Piaget's structural developmental psychology, cognitive aspects of identification are highlighted. The identification is seen as a part of a structural cognitive level of a more general process of imitation, or a process of social participation. The identification, to this approach, also shows discrepancy with psychoanalytic theory—on the one hand it is not linked exclusively to the needs and relationships from the primitive parent-child interaction and on the other hand, it is not established completely and irreversibly_ and works more like development tasks solutions. Cognitive approaches also dif- 
fer from social learning theory because at first, the reinforcing have their main role associated with cognitive coping for the establishment of social or success standards (Piaget, 1932, 1959). Important contribution for this approach comes from the Kohlberg's theory of moral development, which postulates that internalization occurs to the extent that the contact of children with physical and social environment gradually promotes the appropriate adjustments to their stage of development. His research indicated that aspects of moral development are continuous and resulting from the reaction to the entire social world and not as a product of a particular stage, a particular concept (reciprocity), or a particular type of social relationship (peer relations). The development of a morality, of identification with authority, depends on the assumption of social role and the development of concepts such as reciprocity, justice and well-being of the group (Kohlberg, 1963).

In the face of conceptual diversity some distinctions are necessary for better understanding of the identification concept in this paper. The first distinction is between process and outcome. The processual identification occurs towards to the dynamics established for a person to assume the behaviors of others and the structural identification refers to the degree of similarity or guidance with respect to a model person (function model), meaning that it can be seen as the result of the process. The second distinction made is related to differences between imitation and identification. In the case of imitation, this would involve the perception and adoption of the behavior of a model by an observer (Bandura, 1963, 1969). However, imitations at an elementary level may occur, without necessarily lead to cognitive impairment, while the identification process produces changes in cognitive structure, self-knowledge and behavior oriented to action. Thus, the concept of identification has a greater comprehensiveness than the term derived from the learning theory model (Remschmidt \& Mattejat, 1999).

\subsection{Family Identification Patterns}

The term "patterns of identifications” used in this paper is derived from Remschimidt \& Mattejat's studies carried out since the 70s with children of schizophrenic and depressed parents (Remschmidt \& Mattejat, 1999). The authors developed a measurement system that implied on the degree of similarity between descriptions that a subject under evaluation had of himself and others, that is their level of identification. Their work led to a testFamilien-Identifikations-Test-FIT (Family Identification Test), which aimed to measure these patterns by calculating a correlation profile. The FIT methodology involves the use of a list of adjectives and one format of answers that allow self-description and the description of other significant persons. Thus, the fundamental design of the FIT is to obtain personal descriptions of the subjects (actual self, ideal self, other's concept) in assessment and determine, through correlation coefficients, the similarity among these concepts. The correlation coefficients, in turn, are interpreted as indicators of self-congruence of a person and the identification with the other members of the family (Remschmidt \& Mattejat, 1999).

\subsection{Self-Concept}

The main theoretical reference about the self-concept employed on FIT have its origins in Carl Rogers personality theory. The differentiation of self lies in part on the tendency to self-realization, in which part of the individual's experience becomes differentiated and symbolized in awareness of being, consciousness of operate, that is, their self-experience. The interaction of self-experience with an environment, which comprises significant others, fosters the development of a concept of him/herself - the self-as object of perception on experimental field. So the perceptions of their own characteristics, or "him/herself" towards others and to various aspects of life, together with the values attached to these perceptions configure the self or self-concept that may be available to consciousness at a specific time, but, characteristically, is a fluid and changing process. The term, self or self-concept in Rogerian conception is used to refer to one's vision about himself, his self-structure (Rogers, 1951, 1959). In their update of concept, complemented with the cognitive theories, Remschimidt \& Mattejat postulated that the self is the cognitive representation that an individual makes of himself, which is developed from interactions (experience) of the individual with his environment. Such interactions are generalized to include all cognitions likely to become conscious, which the individual relates to himself as the bearer of certain traits. Thus, the self-concept is used to control the activity and to structure new experiences, that is, the self affects the person's action trends and his/her interpretation of situations (Remschmidt \& Mattejat, 1999).

In the conception of FIT, the self-concept can be considered as a cognitive schema, because it is structured, on the one hand, from the individual and the others experiences (assimilation). These experiences can be changed 
based on past experiences (accommodation) producing a scheme in relatively high level of generalization. So each developmental challenge related to individual experience can promote changes in self-concept and characterize thus self-schemes, said contextual. In addition, the individual tends to seek consistency of his self-concept looking for experiences that give meaning and confirm himself and to avoid experiences that place him in question (Remschmidt \& Mattejat, 1999).

\subsection{Actual Self, Ideal Self and Self-Congruence}

The self-concept differentiates two aspects: a descriptive one, concerning to the actual self-image- "How I am" and a normative one, concerning to the ideal self-image- - "How I want to be". Self-congruence refers to the consistency between them-the actual self and the ideal self. Discrepancies between actual and the ideal selfimages imply in a change or pressure developing in the direction of a change in the search for convergence between the actual self and the ideal self (Lynch, La Guardia, \& Ryan, 2009). In addition, discrepancies may indicate both psychological problems that affect the functioning of the person, but can also represent a stimulus and positively affect the development (Remschmidt \& Mattejat, 1999).

\subsection{Other's Concept and Identification}

The ideas that form on the individuality of others, especially of interaction partners constitute the concepts of "other". Similar to what was discussed about the self concept, others' concept represent generalizations of individual interactions with the environment where the individual relates to others, as individuals with their own characteristics and in the same way as cognitive schemes that have an emotional and motivational burden. The self-concept and other's concepts develop in parallel and influence each other by internal comparative cognitive processes in which the individual relates to others and conducts assessments noting similarities and/or differences. The underlying processes and changes in the self-concept, and the other's concepts, occur to a large extent by the experiences and reactions of the others significant to the person (Remschmidt \& Mattejat, 1999).

Thus, as more positive is the emotional value of the other's concept greater is the probability of ideal identification with that person. Individuals often have the tendency to evaluate in emotionally positive way their most important reference persons and ideally identify with them, namely, to achieve a minimum level of agreement between the ideal self-concept and concepts of the other. When this is not possible, it is experienced by the individual as a cognitive inconsistency and the cohesion of the social system could be questioned (Remschmidt \& Mattejat, 1999).

At this point, referring to the definition of identification postulated by FIT's authors as a concordance between self-concept and other's concept of an individual, we can assume that as higher is the concordance between these concepts, greater is the individual's identification with the other person. It is, therefore, a concept of structural identification related to cognitive representations of a person (Remschmidt \& Mattejat, 1999).

The FIT can be performed with isolated individuals to obtain information on their identifications. However, the test is best stated in terms of family diagnosis, implementation with the adolescent/child's parents evaluation and possibly with other people in their social context (Teodoro, 2000). Usually, the structural identification with the people currently living with the person searched (family home) is investigated. The parallel test reliability values for self-congruence and identifications are 0.68 and 0.83 . Test-retest reliability of the test values determined after a brief period was on average 0.78 (retest after two weeks) and 0.75 (retest after 6 weeks) (Remschmidt \& Mattejat, 1999).

Since it was created, some studies have used the FIT in evaluating samples of children and youth, in comparative studies of healthy populations with other with some type of mental health problems, particularly depression, separation anxiety disorder, attention deficit hyperactivity disorder and unspecified mental disorders with clinical (Blatter-Meunier, Lavallee, \& Schneider, 2013; Käppler, 2005; Käppler, 1998; Meyer, Mattejat, König, Wehmeier, \& Remschmidt, 2001; Oswald, 2008) and non-clinical samples (Graeff-Martins et al., 2006; Teodoro, 2000). A Brazilian multicenter project developed in four state capitals inspired by a Swiss Study-the Access Mental Health Care in Children (Käppler \& Mohler, 2006; Kappler et al., 2008) investigated, among other relevant health issues, family identification patterns in the public health system (Amparo et al., 2010). The public health system — called the Unified Health System (SUS, acronym in Portuguese) in Brazil, is based on the principles of regionalization and hierarchy of services and, with regard to attention the mental health of children and adolescents, it is directed for specialized services called Psychosocial Care Centers of Children and Youth 
(CAPSi, acronym in Portuguese). Those services are still insufficient to meet the demands of the target population (Rodrigues, Pedroso, Pontes, \& Käppler, 2015) thus it is necessary to investigate the customer base that frequents these services nowadays.

\subsection{The Present Study}

This study, linked to the Brazilian multicenter study (Amparo et al., 2010) aims to examine family identification patterns obtained with the FIT by adolescents subgroups from different contexts including a subgroup of outpatient treatment for mental disorders and subgroups of students from regions with low and high Human Development Index (HDI) in the direction of analyzing the discriminant properties of the instrument and its utility to monitor health outcomes in adolescents. It was hypothesized that families with adolescents in treatment for mental disorders would report lower levels of self-congruence and identification than families with adolescent students without disorders.

\section{Methods}

\subsection{Participants}

Adolescents (12 - 18 years old) and their parents were recruited as part of an exploratory and cross sectional study of a multicenter Brazilian project research in four Brazilian state capitals: Brasilia, Porto Alegre, Fortaleza and Belém (Amparo et al., 2010). These cities are included in four of five major geopolitical regions of the country: Midwest, South, Northeast and North, respectively. The data were integrated into a national database for analyzes. The sample was selected in a multistage sampling from three groups (clusters): a clinical group (CG), a group of public schools students (PG) and a group of private schools students (PrG) (Amparo et al., 2010; Morais, Amparo, Fukuda, \& Brasil, 2012; Rodrigues et al., 2015). In order to form clinical group (CG) public and private outpatient services were identified in the four targeted cities of the research (preferably, Psychosocial Care Centers for Children and Youth). After authorization of the selected institutions managers, oral invitations were performed to all adolescents and caregivers who were attending at the waiting rooms of those services within the stipulated period for data collection. Those who accepted the oral invitation, were asked to sign the consent form for participation in the study. After these procedures, the instruments were applied in private settings for adolescents and caregivers, separately. Student groups (PG and PrG) were selected in two types of schools: public (with low HDI) and private (with high HDI), both located geographically close to selected health services when formed the clinical group (CG). After authorization of the school principals, invitations were conducted in the classrooms for all students in the age group under study. Those who agreed to participate took a letter to their caregivers to obtain consent for their own participation as well as of their caregivers. After these procedures, the instruments were applied individually or in small groups. Participants included 1.082 adolescents (583 females and 499 males), and 479 caregivers (350 maternal figures and 129 paternal figures). The mean age of adolescents from total sample was $15.30(S D=1.60)$ years old. There was no difference in age, between the sexes $t(1080)=-1.436, p=0.151$. The mean ages by group were $M=15.4(S D=1.47)$ years old, $M=15.53(S D=1.61)$ years old, and $M=14.49(S D=1.68)$ years old, respectively, for PG, PrG and CG and the differences were significant $[F(2,141.753)=29.242, p<0.001]$. ANOVA multiple comparisons performed with the post hoc Hochberg test revealed that adolescents from clinical group (CG) had mean ages significantly lower than PG (mean difference $=-0.908, p<0.001$ ) and that of PrG (mean difference $=-1.036, p<0.001$ ). There was no difference between the ages for groups of students (PG and PrG) (Rodrigues et al., 2015).

It was obtained approval from the Ethics Research Committee in Human Beings of the Catholic University of Brasília (CEP/UCB No.86/2006) and participants and institutions selected were asked to signing the term of free and informed consent stating their knowledge and acceptance of the research.

\subsection{Instruments}

The Family Identification Test (FIT). This instrument was developed originally in two equivalent formats for test application-paperboard and questionnaire—both organized based on twelve adjectives (active, talkative, calm, self-confident, independent, anxious, understanding, considerate, friendly, nervous, moody and content) that are used to assess the extent that the person perceives and identifies himself with other family members. These attributes keep match with three of the five factors of the Big Five model, namely, extraversion, agreeableness and neuroticism (McCrae \& John, 1992), the first two factors, due to its interactional relevance, and the 
latter because of its clinical significance. The extraversion factor was represented at the FIT in two distinct aspects, the social activity (active, talkative and calm) and assertiveness (self-confident, independent and anxious) defined by its authors as fundamental in the perception of one's personality (Remschmidt \& Mattejat, 1999). In assessing the results obtained with the FIT, in its Instruction Manual two possible levels of intra-individual assessment and two possible levels of inter-individual assessment are indicated. In the intra-individual level can be assessed: 1) the raw scores, which are descriptions of yourself (How I am , How I want to be) and others (How is my mother, How is my father, etc.) called adjective level and 2) the level of correlation, it means, similarity between descriptions of yourself and others, called identification level (self-congruence, actual and ideal identifications), which obtains the correlation measures between concepts measured on the first level (adjective) named execution variables. In the inter-individual level can be assessed: 1) the level of inter-individual descriptions consistency and 2) the level of inter-individual identifications consistency. The analysis focus in this article is the second level of intra-individual assessment, i.e. the degree of correlation or identification. Guidelines with cutoff points for self-congruence and identifications correlations values, based on validation studies, provide parameters for interpreting results: very low $=-1.00$ to 0.29 , low $=0.30$ to 0.39 , medium $=0.40$ to 0.79 , high $=$ 0.80 to 0.89 and very high $=0.90$ to 1.00 (Remschmidt \& Mattejat, 1999). The FIT was translated into Brazilian Portuguese and validated, on its paperboard format (Teodoro, 2000). The questionnaire format used in this research keeps the adjustments made by Käppler (Käppler, 2004). Thus, to the adolescent was asked to describe himself, his father, his mother and his grandfather or grandmother (grandparent) considered important; to the caregiver was asked to describe himself (or herself), the adolescent in investigation and their care partner with adolescent. In the FIT questionnaires, the person searched must indicate to what extent the adjectives could be applied to each person described. The possible answers were given on a Likert scale of five points ranging from one "does not match" to five "match totally".

Thus, from the evaluation version administered to the adolescents were obtained ten correlation coefficients and from the version given to the caregiver (father and mother versions) were obtained six correlation coefficients for each. An overview of the execution variables (correlation coefficients) presented in this study are provided in Table 1. This implies that the variables that will be analyzed in this paper are those reported by adolescents. The results for the caregivers will be reported as Appendices to this article.

Sociodemographic Data. Background variables taken into account in the analyses came from adolescents and their caregivers. Data collected from the adolescents were age, sex, and the Family Affluent Scale II (FAS II). The FAS is a socioeconomic indicator addressed to adolescent population, which includes family car ownership, having their own unshared room, the number of computers at home, and how many times they spent on holidays in the past 12 months. Three FAS levels were considered: low affluence (scores $=0,1,2$ ), medium (scores $=3,4,5$ ), and high (scores $=6,7,8,9$ ) (Boyce, Torsheim, Currie, \& Zambon, 2006). Data collected from the caregivers taken into consideration in this paper were which parental figure the caregiver represented: maternal or paternal.

\subsection{Statistical Analysis}

In assessing of the data obtained with the FIT on the identification level, the execution variables were obtained and presented by Pearson correlation coefficients, ten in number for the version administered to adolescents and six for the version administered to the caregiver (father and mother version). The values obtained from Pearson correlations were transformed into Fisher's $Z$ scores by the Equation (1)

$$
Z=0.5[\ln (1+r)-\ln (1-r)]
$$

where $\ln$ is the natural logarithm. This data transformation aims to ensure normality of the sample and allows one to perform the calculation of means, standard deviations, and percentile ranges, by groups (students and clinical). When $r$ was exactly equal to one $(r=1)$ an approximation was used, with $99 \%$ of accuracy, which results in an approximate value of $Z=2.65$. Following, these $Z$ scores were transformed into correlations again to the presentation of results (Fisher, 1921). A MANOVA was conducted to test the hypothesis that there would be one or more means differences between the target groups (PG, PrG and CG) and the results of FIT. The MANOVA was followed up by a MANCOVA in order to investigate the influence of sex, age and socioeconomic status (FAS) as covariate factors by groups of adolescents from different backgrounds (PG, PrG and CG). It was used the Cohen $d$ to estimate the effect size (Cohen, 1988). The decision level adopted for all analyzes was an alpha of 0.05 . 
Table 1. Descriptive statistics of FIT’s execution variables by adolescents groups.

\begin{tabular}{|c|c|c|c|c|c|c|c|c|c|}
\hline \multirow{3}{*}{ FIT's execution variables } & \multirow{3}{*}{ Groups } & \multicolumn{4}{|c|}{ Fisher's $Z$ scores } & \multicolumn{4}{|c|}{ Pearson $r$ transformed back } \\
\hline & & \multirow{2}{*}{ Mean } & \multirow{2}{*}{$S D$} & \multicolumn{2}{|c|}{ 95\% CI for Mean } & \multirow{2}{*}{ Mean } & \multirow{2}{*}{$S D$} & \multicolumn{2}{|c|}{ 95\% CI for Mean } \\
\hline & & & & Lower & Upper & & & Lower & Upper \\
\hline \multirow{3}{*}{ SC } & PG & 0.52 & 0.62 & 0.46 & 0.57 & 0.47 & 0.55 & 0.43 & 0.52 \\
\hline & PrG & 0.66 & 0.66 & 0.59 & 0.73 & 0.58 & 0.58 & 0.53 & 0.62 \\
\hline & CG & 0.56 & 0.69 & 0.45 & 0.66 & 0.51 & 0.60 & 0.42 & 0.58 \\
\hline \multirow{3}{*}{ AIM } & PG & 0.44 & 0.52 & 0.39 & 0.49 & 0.42 & 0.48 & 0.37 & 0.45 \\
\hline & PrG & 0.50 & 0.50 & 0.45 & 0.55 & 0.46 & 0.47 & 0.42 & 0.50 \\
\hline & CG & 0.46 & 0.54 & 0.37 & 0.54 & 0.43 & 0.49 & 0.36 & 0.49 \\
\hline \multirow{3}{*}{ AIF } & PG & 0.38 & 0.55 & 0.32 & 0.43 & 0.36 & 0.50 & 0.31 & 0.40 \\
\hline & PrG & 0.49 & 0.50 & 0.44 & 0.54 & 0.45 & 0.46 & 0.41 & 0.49 \\
\hline & CG & 0.38 & 0.51 & 0.31 & 0.46 & 0.37 & 0.47 & 0.30 & 0.43 \\
\hline \multirow{3}{*}{ AIG } & PG & 0.42 & 0.55 & 0.36 & 0.47 & 0.39 & 0.50 & 0.35 & 0.44 \\
\hline & PrG & 0.50 & 0.50 & 0.45 & 0.55 & 0.46 & 0.46 & 0.42 & 0.50 \\
\hline & CG & 0.46 & 0.53 & 0.38 & 0.54 & 0.43 & 0.49 & 0.36 & 0.50 \\
\hline \multirow{3}{*}{ IIM } & PG & 0.58 & 0.66 & 0.52 & 0.64 & 0.52 & 0.58 & 0.48 & 0.57 \\
\hline & $\operatorname{PrG}$ & 0.69 & 0.68 & 0.62 & 0.76 & 0.60 & 0.59 & 0.55 & 0.64 \\
\hline & CG & 0.62 & 0.61 & 0.53 & 0.71 & 0.55 & 0.55 & 0.48 & 0.61 \\
\hline \multirow{3}{*}{ IIF } & PG & 0.60 & 0.69 & 0.53 & 0.66 & 0.54 & 0.60 & 0.49 & 0.58 \\
\hline & $\operatorname{PrG}$ & 0.78 & 0.64 & 0.72 & 0.85 & 0.65 & 0.57 & 0.62 & 0.69 \\
\hline & CG & 0.53 & 0.70 & 0.42 & 0.63 & 0.48 & 0.60 & 0.40 & 0.56 \\
\hline \multirow{3}{*}{ IIG } & PG & 0.69 & 0.71 & 0.63 & 0.76 & 0.60 & 0.61 & 0.55 & 0.64 \\
\hline & $\operatorname{PrG}$ & 0.85 & 0.68 & 0.78 & 0.91 & 0.69 & 0.59 & 0.65 & 0.72 \\
\hline & CG & 0.76 & 0.68 & 0.66 & 0.87 & 0.64 & 0.59 & 0.58 & 0.70 \\
\hline \multirow{3}{*}{ SMF } & PG & 0.59 & 0.67 & 0.53 & 0.66 & 0.53 & 0.59 & 0.49 & 0.58 \\
\hline & $\operatorname{PrG}$ & 0.65 & 0.67 & 0.58 & 0.72 & 0.57 & 0.59 & 0.52 & 0.61 \\
\hline & CG & 0.56 & 0.67 & 0.45 & 0.66 & 0.51 & 0.59 & 0.43 & 0.58 \\
\hline \multirow{3}{*}{ SMG } & PG & 0.66 & 0.63 & 0.60 & 0.72 & 0.58 & 0.56 & 0.54 & 0.61 \\
\hline & PrG & 0.66 & 0.65 & 0.59 & 0.73 & 0.58 & 0.57 & 0.53 & 0.62 \\
\hline & CG & 0.62 & 0.61 & 0.53 & 0.71 & 0.55 & 0.55 & 0.48 & 0.61 \\
\hline \multirow{3}{*}{ SFG } & PG & 0.62 & 0.66 & 0.56 & 0.68 & 0.55 & 0.58 & 0.51 & 0.59 \\
\hline & PrG & 0.66 & 0.67 & 0.60 & 0.73 & 0.58 & 0.59 & 0.53 & 0.62 \\
\hline & CG & 0.56 & 0.63 & 0.47 & 0.66 & 0.51 & 0.56 & 0.44 & 0.58 \\
\hline
\end{tabular}

Note: PG = Public School Group, PrG = Private School Group, CG = Clinical Group, AIM = actual identification with mother, AIF = actual identification with father, AIG = actual identification with grandparent, IIM = ideal identification with mother, IIF = ideal identification with father, IIG = ideal identification with grandparent, SMF= similarity mother-father, SMG = similarity mother-grandparent, SFG = similarity father-grandparent.

\section{Results}

\subsection{Descriptive Statistics and Correlations}

Table 1 presents means and standard deviations obtained to the FIT's execution variables by adolescent groups (PG, PrG and CG) derived from Pearson correlations $\left(r^{2}\right)$ transformed into Fisher's $Z$ scores and converted again into Pearson correlations. Figure 1 summarizes means differences in Pearson's correlations transformed back.

\subsection{Multivariate Analysis of Variance (MANOVA)}

Prior to conducting the MANOVA, a series of Pearson correlations were performed between FIT’s execution 


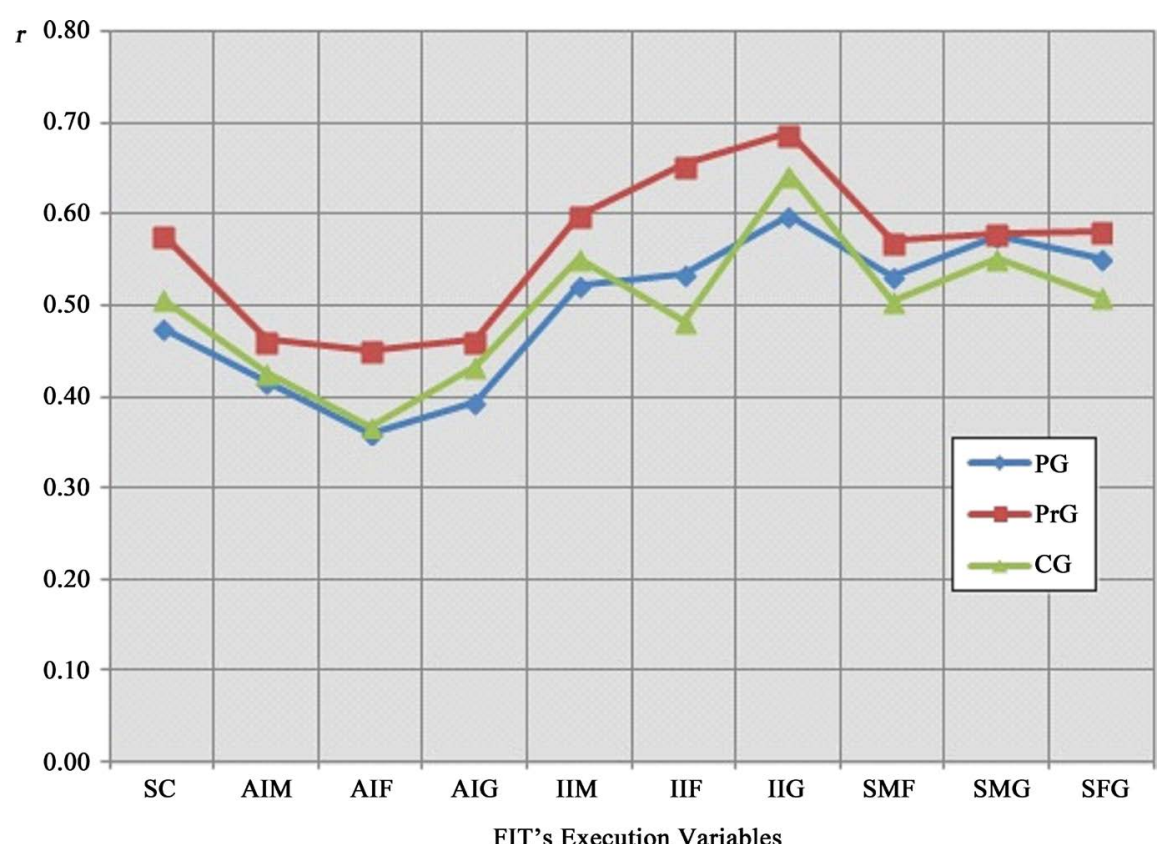

Figure 1. FIT's execution variables: means by groups (PG, PrG and CG).

variables and potential mediators in order to test the MANOVA assumption that the dependent variables would be correlated with each other in a moderate range (Meyers, Gamst, \& Guarino, 2006) (Table 2). Additionally, the Box's $M$ value of 128.54 was associated with a $p<0.137$ suggesting the appropriateness of the MANOVA. A one-way multivariate analysis of variance was conducted to test the hypothesis that there would be one or more mean differences between adolescents groups (PG, PrG and CG) and FIT's $Z$ scores. A statistically significant MANOVA effect was obtained, Wilk's $\Lambda=0.958, F(20,1962)=2.110, p<0.003, \eta^{2}=0.021$. The homogeneity of variance assumption was tested and considered satisfied based on a series of Levene's $F$ tests (Table 3). A series of one-way ANOVA's on each of the ten dependent variables was conducted. As can be seen in Table 3, four of the ANOVA's were statistically significant, with effect sizes (partial $\eta^{2}$ ) ranging from 0.01 to 0.02. Thus, MANOVA indicated group differences on four of ten FIT's execution variables: self-congruence, actual and ideal identification with father and ideal identification with grandparent (grandfather or grandmother). Planned comparisons between groups (PG, PrG and CG) indicated lower self-congruence (SC), actual identification with father (AIF) and grandparent (AIG), ideal identifications with mother (IIM), father (IIF) and grandparent (IIG) in adolescents from PG than PrG with effect sizes (Cohen's $d$ ) ranging from 0.17 (IIM) to 0.28 (IIF) and, lower actual (AIF) and ideal (IIF) identifications with father in adolescents from CG than PrG, with effect sizes (Cohen's $d$ ) ranging from 0.20 (AIF) to 0.39 (IIF). No statistically significant differences were found between PG and CG groups.

\subsection{Multivariate Analysis of Covariance (MANCOVA)}

A MANCOVA was used to check whether the independent variables were influencing the dependent variable groups (PG, and GC PrG) after removing the effect of the covariate factor (Table 4). When sex, age and socioeconomic status (FAS) were added as covariates in the MANCOVA the effects became a bit weaker, Wilk's $\Lambda=0.963, F(20,1952)=1.881, p<0.010, \eta^{2}=0.019$ but univariate outcomes (adjusted for gender, age and socioeconomic status) showed the same linear tendency to differences the groups for actual (AIF) and ideal (IIF) identification with father and ideal identification with grandparent (IIG) and post hoc (Bonferroni) analyzes confirmed the same differences between groups of adolescents (PG, PrG and CG) already reported with the MANOVA except for ideal identification with mother (IIM) that disappeared.

\section{Discussion and Conclusions}

The aim of this study was to investigate differences in family identification patterns between adolescents sub- 
Table 2. Correlations among sex, age, socioeconomic status (FAS) and fisher's Z scores of Adolescents FIT's execution variables.

\begin{tabular}{|c|c|c|c|c|c|c|c|c|c|c|c|c|c|c|}
\hline & & \multicolumn{3}{|c|}{ Potential mediators } & \multicolumn{10}{|c|}{ FIT's execution variables } \\
\hline & & Sex & Age & FAS & SC & AIM & AIF & AIG & IIM & IIF & IIG & SMF & SMG & SFG \\
\hline \multirow{2}{*}{ Sex } & $\mathrm{r}$ & 1 & & & & & & & & & & & & \\
\hline & $\mathrm{n}$ & 1082 & & & & & & & & & & & & \\
\hline \multirow{2}{*}{ Age } & $\mathrm{r}$ & 0.04 & 1 & & & & & & & & & & & \\
\hline & $\mathrm{n}$ & 1082 & 1082 & & & & & & & & & & & \\
\hline \multirow{2}{*}{ FAS } & $\mathrm{r}$ & $0.07^{*}$ & -0.04 & 1 & & & & & & & & & & \\
\hline & $\mathrm{n}$ & 1081 & 1081 & 1081 & & & & & & & & & & \\
\hline \multirow{2}{*}{ SC } & $\mathrm{r}$ & $0.20^{* *}$ & -0.06 & 0.11 & 1 & & & & & & & & & \\
\hline & $\mathrm{n}$ & 1082 & 1082 & 1081 & 1082 & & & & & & & & & \\
\hline \multirow{2}{*}{ AIM } & $\mathrm{r}$ & $0.07^{*}$ & $0.07^{*}$ & $0.09^{* *}$ & $0.50^{* *}$ & 1 & & & & & & & & \\
\hline & $\mathrm{n}$ & 1082 & 1082 & 1081 & 1082 & 1082 & & & & & & & & \\
\hline \multirow{2}{*}{ AIF } & $\mathrm{r}$ & $0.17^{* *}$ & -0.05 & $0.09^{* *}$ & $0.46^{* *}$ & $0.51^{* *}$ & 1 & & & & & & & \\
\hline & $\mathrm{n}$ & 1055 & 1055 & 1054 & 1055 & 1055 & 1055 & & & & & & & \\
\hline \multirow{2}{*}{ AIG } & $\mathrm{r}$ & $0.12^{* *}$ & -0.03 & 0.06 & $0.55^{* *}$ & $0.55^{* *}$ & $0.54^{* *}$ & 1 & & & & & & \\
\hline & $\mathrm{n}$ & 1037 & 1037 & 1036 & 1037 & 1037 & 1022 & 1037 & & & & & & \\
\hline \multirow{2}{*}{ IIM } & r & 0.02 & -0.03 & $0.12^{* *}$ & $0.44^{* *}$ & $0.50^{* *}$ & $0.29^{* *}$ & $0.35^{* *}$ & 1 & & & & & \\
\hline & $\mathrm{n}$ & 1082 & 1082 & 1081 & 1082 & 1082 & 1055 & 1037 & 1082 & & & & & \\
\hline \multirow{2}{*}{ IIF } & $\mathrm{r}$ & $0.09^{* *}$ & -0.05 & $0.14^{* *}$ & $0.35^{* *}$ & $0.31^{* *}$ & $0.49^{* *}$ & $0.31^{* *}$ & $0.41^{* *}$ & 1 & & & & \\
\hline & $\mathrm{n}$ & 1027 & 1027 & 1026 & 1027 & 1027 & 1025 & 996 & 1027 & 1027 & & & & \\
\hline \multirow{2}{*}{ IIG } & $\mathrm{r}$ & 0.05 & -0.03 & $0.09^{* *}$ & $0.34^{* *}$ & $0.30^{* *}$ & $0.24^{* *}$ & $0.48^{* *}$ & $0.43^{* *}$ & $0.42^{* *}$ & 1 & & & \\
\hline & $\mathrm{n}$ & 1012 & 1012 & 1011 & 1012 & 1012 & 996 & 1010 & 1012 & 998 & 1012 & & & \\
\hline \multirow{2}{*}{ SMF } & $\mathrm{r}$ & 0.03 & -0.04 & $0.12^{* *}$ & $0.29^{* *}$ & $0.43^{* *}$ & $0.48^{* *}$ & $0.36^{* *}$ & $0.49^{* * *}$ & $0.50^{* *}$ & $0.24^{* *}$ & 1 & & \\
\hline & $\mathrm{n}$ & 1047 & 1047 & 1046 & 1047 & 1047 & 1045 & 1014 & 1047 & 1021 & 994 & 1047 & & \\
\hline \multirow{2}{*}{ SMG } & $\mathrm{r}$ & -0.02 & $-0.07^{*}$ & $0.07^{*}$ & $0.29^{* *}$ & $0.45^{* *}$ & $0.30^{* *}$ & $0.48^{* *}$ & $0.58^{* *}$ & $0.26^{* *}$ & $0.44^{* *}$ & $0.51^{* *}$ & 1 & \\
\hline & $\mathrm{n}$ & 1031 & 1031 & 1030 & 1031 & 1031 & 1014 & 1029 & 1031 & 994 & 1008 & 1016 & 1031 & \\
\hline \multirow[t]{2}{*}{ SFG } & $r$ & $0.065^{*}$ & -0.05 & 0.05 & $0.26^{* *}$ & $0.34^{* *}$ & $0.47^{* *}$ & $0.46^{* *}$ & $0.29^{* *}$ & $0.59^{* *}$ & $0.46^{* *}$ & $0.54^{* *}$ & $0.47^{* *}$ & 1 \\
\hline & $\mathrm{n}$ & 1024 & 1024 & 1023 & 1024 & 1024 & 1022 & 1022 & 1024 & 998 & 998 & 1016 & 1016 & 1024 \\
\hline
\end{tabular}

Note: ${ }^{*} p<0.05,{ }^{* *} p<0.01$, FAS = socioeconomic status, SC = self-congruence, AIM = actual identification with mother, AIF $=$ actual identification with father, AIG = actual identification with grandparent, IIM = ideal identification with mother, IIF = ideal identification with father, IIG = ideal identification with grandparent, SMF= similarity mother-father, SMG = similarity mother-grandparent, SFG = similarity father-grandparent.

Table 3. MANOVA tests of groups differences.

\begin{tabular}{|c|c|c|c|c|c|c|c|c|c|c|c|}
\hline \multirow{3}{*}{$\begin{array}{l}\text { FIT's execution } \\
\text { variables }\end{array}$} & \multirow{2}{*}{\multicolumn{2}{|c|}{ Levene’s Test }} & \multirow{2}{*}{\multicolumn{3}{|c|}{ Univariate Tests }} & \multicolumn{6}{|c|}{ Contrasts } \\
\hline & & & & & & \multicolumn{3}{|c|}{ PrG vs PG } & \multicolumn{3}{|c|}{ PrG vs CG } \\
\hline & $F_{(2,989)}$ & $p$ & $F_{(2,989)}$ & $p$ & $\eta^{2}$ & $M D$ & $p$ & Cohen's $d$ & $M D$ & $p$ & Cohen's $d$ \\
\hline SC & 3.06 & 0.048 & 5.11 & $0.006^{*}$ & 0.010 & 0.14 & $0.002^{*}$ & 0.23 & 0.10 & 0.091 & 0.15 \\
\hline AIM & 1.00 & 0.367 & 1.30 & 0.272 & 0.003 & 0.06 & 0.113 & 0.11 & 0.04 & 0.362 & 0.08 \\
\hline AIF & 0.70 & 0.494 & 4.88 & $0.008^{*}$ & 0.010 & 0.11 & $0.003^{*}$ & 0.21 & 0.10 & $0.039^{*}$ & 0.20 \\
\hline AIG & 0.17 & 0.842 & 2.67 & 0.070 & 0.005 & 0.09 & $0.022^{*}$ & 0.16 & 0.04 & 0.450 & 0.07 \\
\hline IIM & 1.39 & 0.250 & 2.89 & 0.056 & 0.006 & 0.11 & $0.017^{*}$ & 0.17 & 0.07 & 0.255 & 0.11 \\
\hline IIF & 0.78 & 0.458 & 11.57 & $0.001^{*}$ & 0.023 & 0.18 & $0.001^{*}$ & 0.28 & 0.26 & $0.001^{*}$ & 0.39 \\
\hline IIG & 0.01 & 0.989 & 5.00 & $0.007^{*}$ & 0.010 & 0.15 & $0.002^{*}$ & 0.22 & 0.08 & 0.208 & 0.12 \\
\hline SMF & 0.09 & 0.914 & 1.28 & 0.280 & 0.003 & 0.06 & 0.239 & 0.08 & 0.09 & 0.144 & 0.14 \\
\hline SMG & 0.47 & 0.627 & 0.25 & 0.778 & 0.001 & 0.00 & 0.934 & 0.01 & 0.04 & 0.499 & 0.06 \\
\hline SFG & 0.90 & 0.407 & 1.41 & 0.244 & 0.003 & 0.04 & 0.343 & 0.07 & 0.10 & 0.099 & 0.15 \\
\hline
\end{tabular}

Note: ${ }^{*} p<0.05, \mathrm{MD}=$ Mean difference, $\mathrm{SC}=$ self-congruence, $\mathrm{AIM}=$ actual identification with mother, AIF = actual identification with father, AIG = actual identification with grandparent, IIM = ideal identification with mother, IIF = ideal identification with father, IIG = ideal identification with grandparent, SMF= similarity mother-father, SMG = similarity mother-grandparent, SFG = similarity father-grandparent. 
Table 4. MANCOVA tests of groups differences with sex, age and socioeconomic status (FAS) as predictors.

\begin{tabular}{|c|c|c|c|c|c|c|c|c|c|c|c|c|c|c|}
\hline \multirow{3}{*}{$\begin{array}{c}\text { FIT's } \\
\text { execution } \\
\text { variables }\end{array}$} & \multirow{2}{*}{\multicolumn{2}{|c|}{ Sex }} & \multirow{2}{*}{\multicolumn{2}{|c|}{ Age }} & \multirow{2}{*}{\multicolumn{2}{|c|}{ FAS }} & \multirow{2}{*}{\multicolumn{2}{|c|}{ Group }} & \multicolumn{6}{|c|}{ Contrasts } \\
\hline & & & & & & & & & \multicolumn{3}{|c|}{ PrG vs PG } & \multicolumn{3}{|c|}{ PrG vs CG } \\
\hline & $F_{(1,985)}$ & $\eta^{2}$ & $F_{(1,985)}$ & $\eta^{2}$ & $F_{(1,985)}$ & $\eta^{2}$ & $F_{(2,985)}$ & $\eta^{2}$ & $M D$ & $p$ & Cohen's $d$ & $M D$ & $p$ & Cohen's $d$ \\
\hline SC & $51.23^{*}$ & 0.049 & $6.19^{*}$ & 0.006 & 1.21 & 0.001 & 2.91 & 0.006 & 0.12 & $0.021^{*}$ & 0.19 & 0.12 & 0.074 & 0.18 \\
\hline AIM & $7.18^{*}$ & 0.007 & $6.37^{*}$ & 0.006 & 2.32 & 0.002 & 0.39 & 0.001 & 0.03 & 0.490 & 0.06 & 0.04 & 0.407 & 0.08 \\
\hline AIF & $31.49^{*}$ & 0.031 & $5.24^{*}$ & 0.005 & 0.22 & 0.000 & $3.69^{*}$ & 0.007 & 0.10 & $0.015^{*}$ & 0.19 & 0.12 & $0.023^{*}$ & 0.24 \\
\hline AIG & $15.17^{*}$ & 0.015 & 1.73 & 0.002 & 0.00 & 0.000 & 2.01 & 0.004 & 0.09 & $0.045^{*}$ & 0.16 & 0.05 & 0.319 & 0.11 \\
\hline IIM & 0.30 & 0.000 & 1.21 & 0.001 & $6.21^{*}$ & 0.006 & 0.38 & 0.001 & 0.05 & 0.388 & 0.07 & 0.02 & 0.712 & 0.04 \\
\hline IIF & $9.65^{*}$ & 0.010 & $4.45^{*}$ & 0.004 & 1.65 & 0.002 & $7.65^{*}$ & 0.015 & 0.15 & $0.004^{*}$ & 0.23 & 0.26 & $0.001^{*}$ & 0.39 \\
\hline IIG & 3.00 & 0.003 & 1.18 & 0.001 & 0.81 & 0.001 & $2.72^{*}$ & 0.005 & 0.13 & $0.020^{*}$ & 0.19 & 0.08 & 0.289 & 0.11 \\
\hline SMF & 0.65 & 0.001 & 2.42 & 0.002 & $10.91^{*}$ & 0.011 & 0.56 & 0.001 & -0.03 & 0.572 & -0.05 & 0.03 & 0.635 & 0.05 \\
\hline SMG & 0.12 & 0.000 & $4.78^{*}$ & 0.005 & $3.92^{*}$ & 0.004 & 0.73 & 0.001 & -0.04 & 0.414 & -0.07 & 0.02 & 0.735 & 0.03 \\
\hline SFG & $5.92^{*}$ & 0.006 & $4.02^{*}$ & 0.004 & 0.13 & 0.000 & 1.66 & 0.003 & 0.04 & 0.465 & 0.06 & 0.12 & 0.071 & 0.19 \\
\hline
\end{tabular}

Note: ${ }^{*} p<0.05$, FAS = Family Affluence Scale, MD = Mean difference, $\mathrm{SC}=$ self-congruence, $\mathrm{AIM}=$ actual identification with mother, AIF $=$ actual identification with father, AIG = actual identification with grandparent, IIM = ideal identification with mother, IIF = ideal identification with father, IIG = ideal identification with grandparent, SMF= similarity mother-father, SMG = similarity mother-grandparent, SFG = similarity father-grandparent.

groups from different backgrounds (students and clinic) in the direction of analyzing the discriminant properties of the FIT and its utility to monitor health outcomes in adolescents. Initially, it was hypothesized that families with adolescents in treatment for mental disorders would report lower levels of self-congruence and identification than families with adolescent students without disorders but this was only partially confirmed, i.e., the clinical group showed lower identification rates that private school group into two patterns and presented similarity to the public school group in all patterns. The results from the present study indicated patterns of identification that differed more evidently between adolescents from private school and public school, and that were similar between adolescents from clinical group and public school group. Considering this, adolescents from public school identify significantly less with their fathers and grandparents and report less desire to be like their parents and grandparent. Moreover, those public school adolescents reported less self-congruence than the two other groups and although it has achieved a medium level $(r=0.47)$ for self-congruence, the levels for actual identifications with father $(r=0.36)$ and grandparent $(r=0.39)$ were lower than expected and, actual identification with mother $(r=0.42)$ was in a medium level, according to specific normative values of the validation studies (Remschmidt \& Mattejat, 1999). These findings may be indicative of less cohesion in families of these adolescents with low incomes, which affects negatively the self-concept compared to the other analyzed groups.

Regarding the clinical group, lower values of identification related to the father figure were obtained, which indicated that adolescents did not perceive themselves as their parents and did not want to be like them; however, they showed median values in other standards values, including self-congruence which seemed to indicate a clear gap of the father figure in the clinical population. Interestingly, the participation of fathers was lower than the mothers particularly in the clinical and public school groups (9\% and 6.1\%) compared with the private group (20.8\%) and as one could analyze in a recent review study from 47 articles that highlighted that paternal absence might contribute negatively to children's social-emotional adjustment that could persist until adolescence, increasing adolescents' risky behavior and leading to the negative effects on high school graduation (McLanahan, Tach, \& Schneider, 2013). So, the findings in this study can be developed in the future, through longitudinal studies, both in order to clarify the weight of father absence in the rates of self-congruence and identification, as to contribute to psychosocial interventions focused on adolescents at-risk in order to mitigate the problems related with self- concept, self-congruence and other's concept and prevent the persistence of mental problems into adulthood.

\section{Acknowledgements}

We thank Professor Deise Matos do Amparo, PhD in Psychology, National University of Brasilia, Brazilian Coordinator of the multicenter project "Public health services: concepts of mental health and perceptions of the 
service from the perspective of adolescents and their families” and Coordinator of the research team in the city of Brasilia.

We thank Professor Silvia Helena Koller, PhD in Psychology and Education, Federal University of Rio Grande do Sul, Coordinator of the research team in the city of Porto Alegre.

We thank the Psychologist Camila de Aquino Morais, Doctor in Psychology, who during her Masters in Psychology at Federal University of Rio Grande do Sul, Brazil organized the national database and performed the data collection in the city of Porto Alegre.

We thank Foundation for Research Support of the Federal District for financial assistance for the development of the research project "Public health services: concepts of mental health from the perspective of young people and their families" that contributed to the construction of a national database.

We thank National Council for Scientific and Technological Development for financial assistance for the development of the research project "Conceptions and perceptions of mental health services from the perspective of youth and family" that contributed to the construction of a national database.

\section{References}

Amparo, D. M., Brasil, K., Fukuda, C. C., Morais, C. A., Antunes, C., Penso, M. A., Wolff, L. et al. (2010). Concepções de saúde e doença mental na perspectiva de jovens e seus cuidadores Brasília, DF: Universidade Católica de Brasília/Universidade de Brasília.

Bandura, A. (1963). The Role of Imitation in Personality. The Journal of Nursery Education, 18, .

Bandura, A. (1969). Social-Learning Theory of Identificatory Processes. In D. A. Goslin (Ed.), Handbook of Socialization Theory and Research (pp. 213-262). Chicago, IL: Rand McNally \& Company.

Blatter-Meunier, J. C., Lavallee, K. L., \& Schneider, S. (2013). Patterns of Family Identification and Self-Congruence in Childhood Separation Anxiety Disorder. Psychopathology, 47, 57-64. http://dx.doi.org/10.1159/000348629

Boyce, W., Torsheim, T., Currie, C., \& Zambon, A. (2006). The Family Affluence Scale as a Measure of National Wealth: Validation of an Adolescent Self-Report Measure. Social Indicators Research, 78, 473-487. http://dx.doi.org/10.1007/s11205-005-1607-6

Call, K. T., Riedel, A. A., Hein, K., McLoyd, V., Petersen, A., \& Kipke, M. (2002). Adolescent Health and Well-Being in the Twenty-First Century: A Global Perspective. Journal of Research on Adolescence, 12, 69-98. http://dx.doi.org/10.1111/1532-7795.00025

Cohen, J. (1988). Statistical Power Analysis for the Behavioral Sciences (2nd ed.). Hillsdale, NJ: Lawrence Erlbaum Associates.

Erikson, E. H. (1994). Identity: Youth and Crisis. New York: W.W. Norton \& Company (1968).

Fisher, R. A. (1921). On the "Probable Erro" of a Coefficient of Correlation Deduced from a Small Sample. Metron, 1, 3-32.

Freud, S. (2006). O ego e o ID e outros trabalhos. (J. Salomão, Trans.). In J. Strachey (Ed.), Edição Standard Brasileira das Obras Psicológicas Completas de Sigmund Freud (1st ed., Vol. XIX, pp. 101-106). Rio de Janeiro: Imago (1924).

Freud, S. (2006). Publicações pré-psicanalíticas e esboços inéditos (J. Salomão, Trans.). In J. Strachey (Ed.), Edição Standard Brasileira das Obras Psicológicas Completas de Sigmund Freud (1st ed., Vol. I, pp. 129-211). Rio de Janeiro: Imago. (1950).

Garcia, C. (2010). Conceptualization and Measurement of Coping during Adolescence: A Review of the Literature. Journal of Nursing Scholarship, 42, 166-185. http://dx.doi.org/10.1111/j.1547-5069.2009.01327.x

Graeff-Martins, A., Oswald, S., Obst Comassetto, J., Kieling, C., Rocha Gonçalves, R., \& Rohde, L. (2006). A Package of Interventions to Reduce School Dropout in Public Schools in a Developing Country. European Child \& Adolescent Psychiatry, 15, 442-449. http://dx.doi.org/10.1007/s00787-006-0555-2

Kagan, J. (1958). The Concept of Identification. Psychological Review, 65, 296-305. http://dx.doi.org/10.1037/h0041313

Käppler, C. (2004). Access to Mental Health Care in Children (the AMHC-Study): Concepts of Mental Health and Perception of Services from the Perspective of Children, Adolescents and Their Families (4052-103375). Zürich: Zentrum für Kinder- und Jugendpsychiatrie der Universität Zürich.

Käppler, C. (2005). Familienbeziehungen bei hyperaktiven Kindern im Behandlungsverlauf. Kindheit und Entwicklung, 14, 21-29. http://dx.doi.org/10.1026/0942-5403.14.1.21

Käppler, C., \& Mohler, B. (2006). Mental Health and Access to Public Services: The Views of Children, Young People and Their Families. In P. Perrig-Chiello, \& C. Suter (Eds.), Childhood, Youth and Intergenerational Relationships in a Changing Society: Portrait of the National Research Programme NRP 52 (pp. 68-69). Berne: Swiss National Science Foundation. 
Kappler, C. D. O., Goncalves, M., Gianella, D., Zehnder, S., Peng, A., \& Mohler-Kuo, M. (2008). Concepts of Mental Health and Barriers to Help Services from the Perspective of Children and Parents: Recent Results from the AMHC(Access to Mental Health Care in Children)-Study [Special Issue: Abstracts of the XXIX International Congress of Psychology]. International Journal of Psychology, 43, 90.

Käppler, K. C. (1998). Padrões de identificação em famílias: Um estudo comparativo entre crianças com e sem problemas psicológicos. Cadernos de Psicologia, 8, 241-252.

Kohlberg, L. (1963). Moral Development and Identification. In H. W. S. J. Kagan, C. S. N. B. Henry, \& H. G. Richey (Eds.), Child Psychology: The Sixty-Second Yearbook of the National Society for the Study of Education, Part 1 (pp. 277-332). Chicago, IL: University of Chicago Press. http://dx.doi.org/10.1037/13101-008

Lynch, M. F., La Guardia, J. G., \& Ryan, R. M. (2009). On Being Yourself in Different Cultures: Ideal and Actual SelfConcept, Autonomy Support, and Well-Being in China, Russia, and the United States. The Journal of Positive Psychology, 4, 290-304. http://dx.doi.org/10.1080/17439760902933765

McCrae, R. R., \& John, O. P. (1992). An Introduction to the Five-Factor Model and Its Applications. Journal of Personality, 60, 175-215. http://dx.doi.org/10.1111/j.1467-6494.1992.tb00970.x

McLanahan, S., Tach, L., \& Schneider, D. (2013). The Causal Effects of Father Absence. Annual Review of Sociology, 39, 399-427. http://dx.doi.org/10.1146/annurev-soc-071312-145704

Meyer, C., Mattejat, F., König, U., Wehmeier, P. M., \& Remschmidt, H. (2001). Psychische Erkrankung unter mehrgenerationaler Perspektive: Ergebnisse aus einer Längsschnittstudie mit Kindern und Enkeln von stationär behandelten depressiven Patienten. Praxis der Kinderpsychologie und Kinderpsychiatrie, 50, 525-536.

Meyers, L. S., Gamst, G., \& Guarino, A. J. (2006). Applied Multivariate Research: Design and Interpretation. Thousand Oaks, CA: Sage.

Morais, C. A., Amparo, D. M., Fukuda, C. C., \& Brasil, K. T. (2012). Concepções de saúde e doença mental na perspectiva de jovens brasileiros. Estudos de Psicologia (Natal), 17, 369-379. http://dx.doi.org/10.1590/S1413-294X2012000300004

Moreira, J. O. (2004). Édipo em Freud: O movimento de uma teoria. Psicologia em Estudo, 9, 219-227. http://dx.doi.org/10.1590/S1413-73722004000200008

Oswald, S. H. (2008). Familienbeziehungen, Selbstkongruenz und Identifikationsmuster von brasilianischen Kindern mit einer Aufmerksamkeitsdefizit-und Hyperaktivitätsstörung im Behandlungsverlauf: Perspektive des Kindes und der Eltern. Tübingen: Universität Tübingen.

Piaget, J. (1932). The Moral Judgement of the Child. London: Kegan Paul.

Piaget, J. (1959). The Language and Thought of the Child. London: Routledge \& Kegan Paul.

Remschmidt, H., \& Mattejat, F. (1999). Familien-Identifikations-Test (FIT). Handanweisung. Göttingen: Hogrefe, Verlag $\mathrm{GmbH} \& \mathrm{Co}$.

Rodrigues, S. M. S., Pedroso, J. D. S., Pontes, F. A. R., \& Käppler, C. O. (2015). Measuring Health-Related Quality of Life in Adolescents by Subgroups of Students and Outpatient Mental Health Clients. Psychology, 6, 833-845. http://dx.doi.org/10.4236/psych.2015.67082

Rogers, C. R. (1951). Client-Centred Therapy: Its Current Practice, Implications and Theory. Boston: Houghton Mifflin

Rogers, C. R. (1959). A Theory of Therapy, Personality, and Interpersonal Relationships: As Developed in the Client-Centered Framework. In S. Koch (Ed.), Psychology: A Study of a Science. Formulations of the Person and the Social Context (Vol. 3, pp. 184-256). New York: McGraw Hill.

Sófocles (1997). Édipo rei. Rio de Janeiro: EDIOURO.

Teodoro, M. (2000). Habilidades sociais e processos de identificação em crianças e adolescents. Unpublished Master's Dissertation, Belo Horizonte: Universidade Federal de Minas Gerais. Available from Sistema de Bibliotecas UFMG Database (104650006). 


\section{Appendices}

Table S1. Demographic variables distribution.

\begin{tabular}{|c|c|c|c|c|c|c|c|c|c|c|}
\hline \multirow{2}{*}{\multicolumn{2}{|c|}{ Demografic variables }} & \multicolumn{3}{|c|}{ PG } & \multicolumn{3}{|c|}{ PrG } & \multicolumn{3}{|c|}{ CG } \\
\hline & & \multirow[t]{2}{*}{$\mathrm{n}$} & \multirow[t]{2}{*}{$\%$} & \multirow{2}{*}{$\begin{array}{l}\text { Mean }(S D) \\
1.46(0.50)\end{array}$} & \multirow[t]{2}{*}{$\mathrm{n}$} & \multirow[t]{2}{*}{$\%$} & \multirow{2}{*}{$\begin{array}{l}\text { Mean }(S D) \\
1.45(0.50)\end{array}$} & \multirow[t]{2}{*}{$\mathrm{n}$} & \multirow{2}{*}{$\%$} & \multirow{2}{*}{$\begin{array}{l}\text { Mean }(S D) \\
1.48(0.50)\end{array}$} \\
\hline Sex & & & & & & & & & & \\
\hline & female & 276 & 54.1 & & 215 & 54.6 & & 92 & 51.7 & \\
\hline & male & 234 & 45.9 & & 179 & 45.4 & & 86 & 48.3 & \\
\hline \multirow[t]{4}{*}{ Age } & & & & $15.40(1.47)$ & & & $15.53(1.61)$ & & & 14.49 (1.68) \\
\hline & 12 - 13 years old & 62 & 12.2 & & 56 & 14.2 & & 59 & 33.1 & \\
\hline & 14 - 15 years old & 170 & 33.3 & & 119 & 30.2 & & 69 & 38.8 & \\
\hline & 16 - 18 years old & 278 & 54.5 & & 219 & 55.6 & & 50 & 28.1 & \\
\hline \multirow[t]{4}{*}{ FAS } & & & & $1.67(0.64)$ & & & $2.51(0.61)$ & & & $1.78(0.76)$ \\
\hline & low & 220 & 43.1 & & 24 & 6.1 & & 76 & 42.7 & \\
\hline & medium & 241 & 47.3 & & 144 & 36.5 & & 66 & 37.1 & \\
\hline & high & 49 & 9.6 & & 226 & 57.4 & & 36 & 20.2 & \\
\hline \multirow[t]{4}{*}{ With parents } & & & & $1.23(0.42)$ & & & $1.41(0.49)$ & & & $1.11(0.32)$ \\
\hline & mother figure & 106 & 20.8 & & 117 & 29.7 & & 127 & 71.3 & \\
\hline & father figure & 31 & 6.1 & & 82 & 20.8 & & 16 & 9.0 & \\
\hline & Total & 137 & 26.9 & & 199 & 50.5 & & 143 & 80.3 & \\
\hline \multirow[t]{2}{*}{ Without parents } & & 373 & 73.1 & & 195 & 49.5 & & 35 & 19.7 & \\
\hline & Total general & 510 & 100.0 & & 394 & 100.0 & & 178 & 100.0 & \\
\hline
\end{tabular}

Table S2. General sample, N = 1082, adolescent version (12 - 18 years old, 583 females, 499 males).

\begin{tabular}{|c|c|c|c|c|c|c|c|}
\hline \multirow{2}{*}{ General Sample } & \multicolumn{2}{|c|}{$\mathrm{N}$} & \multirow{2}{*}{ Mean } & \multirow{2}{*}{$S D$} & \multicolumn{3}{|c|}{ Percentiles } \\
\hline & valid & missing & & & 25 & 50 & 75 \\
\hline SC & 1082 & 0 & 0.50 & 0.57 & 0.08 & 0.47 & 0.71 \\
\hline AIM & 1082 & 0 & 0.42 & 0.47 & 0.10 & 0.41 & 0.65 \\
\hline IIM & 1082 & 0 & 0.53 & 0.57 & 0.10 & 0.52 & 0.76 \\
\hline AIF & 1055 & 27 & 0.39 & 0.49 & 0.04 & 0.37 & 0.62 \\
\hline IIF & 1027 & 55 & 0.57 & 0.59 & 0.19 & 0.54 & 0.77 \\
\hline SMF & 1047 & 35 & 0.54 & 0.59 & 0.17 & 0.50 & 0.75 \\
\hline AIG & 1037 & 45 & 0.42 & 0.48 & 0.11 & 0.43 & 0.63 \\
\hline IIG & 1012 & 70 & 0.64 & 0.60 & 0.26 & 0.62 & 0.82 \\
\hline SMG & 1031 & 51 & 0.57 & 0.56 & 0.22 & 0.56 & 0.78 \\
\hline SFG & 1024 & 58 & 0.55 & 0.58 & 0.16 & 0.52 & 0.77 \\
\hline
\end{tabular}

Note: SC = self-congruence, AIM = actual identification with mother, AIF = actual identification with father, AIG = actual identification with grandparent, IIM = ideal identification with mother, IIF = ideal identification with father, IIG = ideal identification with grandparent, SMF= similarity mother-father, SMG = similarity mother-grandparent, SFG = similarity father-grandparent. 
Table S3. Clinical sample, $\mathrm{N}=178$, Adolescent version (12-18 years old, 92 females, 86 males).

\begin{tabular}{ccccccccc}
\hline Clinical Sample & \multicolumn{2}{c}{ v } & valid & missing & Mean & SD & \multicolumn{5}{c}{ Percentiles } \\
SC & 178 & 0 & 0.49 & 0.60 & 0.02 & 0.49 & 0.72 \\
AIM & 178 & 0 & 0.41 & 0.49 & 0.02 & 0.44 & 0.68 \\
IIM & 178 & 0 & 0.53 & 0.54 & 0.13 & 0.56 & 0.77 \\
AIF & 174 & 4 & 0.37 & 0.50 & 0.00 & 0.34 & 0.60 \\
IIF & 172 & 6 & 0.48 & 0.60 & 0.00 & 0.47 & 0.73 \\
SMF & 173 & 5 & 0.51 & 0.59 & 0.08 & 0.41 & 0.73 \\
AIG & 172 & 6 & 0.43 & 0.48 & 0.12 & 0.44 & 0.64 \\
IIG & 171 & 7 & 0.64 & 0.59 & 0.23 & 0.65 & 0.82 \\
SMG & 171 & 7 & 0.56 & 0.56 & 0.23 & 0.54 & 0.78 \\
SFG & 172 & 6 & 0.51 & 0.56 & 0.14 & 0.46 & 0.71 \\
\hline
\end{tabular}

Note: SC = self-congruence, AIM = actual identification with mother, AIF = actual identification with father, AIG = actual identification with grandparent, IIM = ideal identification with mother, IIF = ideal identification with father, IIG = ideal identification with grandparent, SMF= similarity mother-father, SMG = similarity mother-grandparent, SFG = similarity father-grandparent.

Table S4. (a) Private school sample, $\mathrm{N}=394$, Adolescent version (12 - 18 years old, 215 females, 179 males). (b) Public school sample, $\mathrm{N}=510$, Adolescent version (12 - 18 years old, 276 females, 234 males).

(a)

\begin{tabular}{|c|c|c|c|c|c|c|c|}
\hline \multirow{2}{*}{ Private school sample } & \multicolumn{2}{|c|}{$\mathrm{N}$} & \multirow{2}{*}{ Mean } & \multirow{2}{*}{$S D$} & \multicolumn{3}{|c|}{ Percentiles } \\
\hline & valid & missing & & & 25 & 50 & 75 \\
\hline SC & 394 & 0 & 0.57 & 0.58 & 0.17 & 0.56 & 0.80 \\
\hline AIM & 394 & 0 & 0.46 & 0.46 & 0.18 & 0.45 & 0.68 \\
\hline IIM & 394 & 0 & 0.59 & 0.59 & 0.18 & 0.58 & 0.80 \\
\hline AIF & 394 & 0 & 0.45 & 0.46 & 0.12 & 0.44 & 0.66 \\
\hline IIF & 385 & 9 & 0.66 & 0.57 & 0.33 & 0.64 & 0.83 \\
\hline SMF & 394 & 0 & 0.57 & 0.58 & 0.21 & 0.55 & 0.78 \\
\hline AIG & 390 & 4 & 0.46 & 0.46 & 0.17 & 0.49 & 0.66 \\
\hline IIG & 381 & 13 & 0.69 & 0.59 & 0.37 & 0.66 & 0.86 \\
\hline SMG & 390 & 4 & 0.58 & 0.57 & 0.21 & 0.56 & 0.78 \\
\hline SFG & 390 & 4 & 0.58 & 0.58 & 0.19 & 0.57 & 0.79 \\
\hline
\end{tabular}

(b)

\begin{tabular}{|c|c|c|c|c|c|c|c|}
\hline \multirow{2}{*}{ Public school sample } & \multicolumn{2}{|c|}{$\mathrm{N}$} & \multirow{2}{*}{ mean } & \multirow{2}{*}{$\mathrm{SD}$} & \multicolumn{3}{|c|}{ Percentiles } \\
\hline & valid & missing & & & 25 & 50 & 75 \\
\hline SC & 510 & 0 & 0.44 & 0.54 & 0.06 & 0.42 & 0.64 \\
\hline AIM & 510 & 0 & 0.40 & 0.47 & 0.06 & 0.37 & 0.62 \\
\hline IIM & 510 & 0 & 0.49 & 0.57 & 0.04 & 0.46 & 0.73 \\
\hline AIF & 487 & 23 & 0.35 & 0.50 & 0.00 & 0.31 & 0.60 \\
\hline IIF & 470 & 40 & 0.53 & 0.60 & 0.16 & 0.46 & 0.74 \\
\hline SMF & 480 & 30 & 0.53 & 0.58 & 0.17 & 0.49 & 0.73 \\
\hline AIG & 475 & 35 & 0.38 & 0.50 & 0.06 & 0.37 & 0.61 \\
\hline IIG & 460 & 50 & 0.60 & 0.61 & 0.19 & 0.56 & 0.77 \\
\hline SMG & 470 & 40 & 0.56 & 0.55 & 0.20 & 0.56 & 0.77 \\
\hline SFG & 462 & 48 & 0.54 & 0.58 & 0.13 & 0.49 & 0.77 \\
\hline
\end{tabular}

Note: SC = self-congruence, AIM = actual identification with mother, AIF = actual identification with father, AIG = actual identification with grandparent, IIM = ideal identification with mother, IIF = ideal identification with father, IIG = ideal identification with grandparent, SMF= similarity mother-father, SMG = similarity mother-grandparent, SFG = similarity father-grandparent. 
Table S5. Mother figure sample, $\mathrm{N}=350$, mother version.

\begin{tabular}{|c|c|c|c|c|c|c|c|}
\hline \multirow{2}{*}{ Mother figure sample } & \multicolumn{2}{|c|}{$\mathrm{N}$} & \multirow{2}{*}{ mean } & \multirow{2}{*}{$S D$} & \multicolumn{3}{|c|}{ Percentiles } \\
\hline & valid & missing & & & 25 & 50 & 75 \\
\hline MSC & 334 & 16 & 0.52 & 0.62 & 0.02 & 0.50 & 0.77 \\
\hline MAIA & 337 & 13 & 0.41 & 0.54 & 0.00 & 0.35 & 0.67 \\
\hline MIIA & 340 & 10 & 0.53 & 0.60 & 0.16 & 0.51 & 0.77 \\
\hline MAIP & 335 & 15 & 0.37 & 0.56 & -0.09 & 0.30 & 0.64 \\
\hline MIIP & 338 & 12 & 0.62 & 0.63 & 0.21 & 0.62 & 0.80 \\
\hline SMPA & 342 & 8 & 0.44 & 0.53 & 0.03 & 0.42 & 0.68 \\
\hline
\end{tabular}

Note: MSC = Mother self-congruence, MAIA $=$ Mother Actual Identification with adolescent, MIIA $=$ Mother Ideal Identification with adolescent, MAIP = Mother Actual Identification with partner, MIIP = Mother Ideal Identification with partner, SMPA = Similarity Mother's partner with adolescent.

Table S6. Father figure sample, $\mathrm{N}=129$, father version.

\begin{tabular}{|c|c|c|c|c|c|c|c|}
\hline \multirow{2}{*}{ Father figure sample } & \multicolumn{2}{|c|}{$\mathrm{N}$} & \multirow{2}{*}{ Mean } & \multirow{2}{*}{$S D$} & \multicolumn{3}{|c|}{ Percentiles } \\
\hline & valid & missing & & & 25 & 50 & 75 \\
\hline FSC & 127 & 2 & 0.66 & 0.62 & 0.19 & 0.63 & 0.86 \\
\hline FAIA & 128 & 1 & 0.49 & 0.56 & 0.08 & 0.45 & 0.75 \\
\hline FIIA & 128 & 1 & 0.59 & 0.62 & 0.11 & 0.58 & 0.82 \\
\hline FAIP & 127 & 2 & 0.48 & 0.54 & 0.07 & 0.49 & 0.73 \\
\hline FIIP & 126 & 3 & 0.63 & 0.60 & 0.27 & 0.59 & 0.82 \\
\hline SFPA & 127 & 2 & 0.49 & 0.51 & 0.13 & 0.51 & 0.73 \\
\hline
\end{tabular}

Note: FSC = Father self-congruence, FAIA = Father Actual Identification with adolescent, FIIA = Father Ideal Identification with adolescent, FAIP = Father Actual Identification with partner, FIIP = Father Ideal Identification with partner, SFPA = Similarity Father's partner with adolescent. 